\title{
OS CONGRESSOS AGRÍCOLAS DO RIO DE JANEIRO E DE PERNAMBUCO E A EDUCAÇÃO (1878) ${ }^{1}$
}

\author{
Maria Isabel Moura Nascimento ${ }^{2}$ \\ Manoel Nelito Matheus Nascimento ${ }^{3}$
}

\section{RESUMO}

Este artigo apresenta um estudo sobre a educação nos Congressos Agrícolas do Rio de Janeiro e de Pernambuco (1878), com o principal objetivo de examinar as propostas de constituição de escolas apresentadas pelos congressistas. Na segunda metade do século XIX, o debate da sociedade brasileira sobre o fim da escravidão e a iminente crise da mãode-obra foi acirrado com a promulgação da Lei do Ventre Livre em 1871, levando a elite agrária, composta principalmente de grandes fazendeiros de café, a propor a criação de instituições escolares para os "libertos" (ingênuos), assim como a criação de asilos e orfanatos de educação agrícola para receber e preparar as crianças para o trabalho. Os discursos apresentados nos Anais dos dois Congressos Agrícolas revelam que a ensino primário e a instrução agrícola eram compreendidos como essenciais para tornar possível a utilização do elemento nacional no serviço agrícola. Consideravam que os ingênuos e demais homens livres deveriam ser "recuperados" para uma vida digna, uma vida de trabalho, por meio da educação.

Palavras-chave: História da Educação; Congresso Agrícola do Rio de Janeiro; Congresso Agrícola do Recife

\section{AGRICULTURAL THE CONGRESS OF RIO DE JANEIRO AND PERNAMBUCO AND EDUCATION (1878)}

\begin{abstract}
This article presents a study on education in Agricultural Congress of Rio de Janeiro and Pernambuco (1878), with the principal objective to examine the proposals for the establishment of schools presented by Congress. In the second half of the nineteenth century, the discussion of Brazilian society about the end of slavery and the impending crisis of labor was fierce with the promulgation of the Law of the Free Womb in 1871, leading the agrarian elite, composed mainly of large farmers coffee, to propose the establishment of educational institutions for " freedmen " ( naïve ), as well as the creation of asylums and orphanages of agricultural education to receive and prepare children for work . Speeches presented in the Proceedings of the two Congresses Agricultural reveal that the primary agricultural education and education were included as essential to make use of the national element in the agricultural service possible. Considered that too naive and free men should be " recovered " to a dignified life, a life of work, through education . Keywords : History of Education ; Agricultural Congress of Rio de Janeiro, Agricultural Congress of Recife.
\end{abstract}

\section{Introdução}

Os Congressos Agrícolas do Rio de Janeiro e de Recife realizados em 1878 reuniram representantes da elite agrária brasileira com o objetivo discutir os problemas que afetavam a grande lavoura, em especial a do café, o principal produto da base econômica Revista HISTEDBR On-line, Campinas, $n^{\circ}$ 52, p. 54-74, set2013 - ISSN: 1676-2584 54 
do país. Estes congressos permitiram pela primeira vez na história do Brasil independente, porém ainda escravista, que grandes e pequenos proprietários de terras debatessem os principais problemas que afetavam a produção agrícola e encaminhassem suas reclamações e reinvindicações direto ao Governo Imperial.

Os dois Congressos Agrícolas promoveram debates sobre a questão da mão-de-obra escrava, chamando a atenção para os trabalhadores livres, que diante da crise não poderiam ser desprezados. Para os congressistas, eles vivem sem

[...] raízes no solo nem espírito de família e levam uma vida quase nômade, contraindo hábitos de ociosidade, dissipação, imoralidade e anarquia, que os levam facilmente ao crime, donde não raro saem impunes, graças à intercessão do novo senhorio [...] As coisas têm chegado a tal ponto, que para muitos homens pobres a única linha divisória entre o livre e o escravo é que este é obrigado a trabalhar e aquele não (CONGRESSO AGRÍCOLA, 1978, p. 91).

Com a Lei do Ventre livre ${ }^{4}$ sancionada em 1871, intensificaram-se as discussões com relação ao problema da libertação dos escravos e sobre os filhos das escravas nascidos após a promulgação da Lei, os chamados ingênuos, que precisavam ser preparados para o trabalho na lavoura.

Os desdobramentos dos debates em torno da Lei do Ventre Livre levou a elite agrária dirigente e dominante, composta principalmente de grandes fazendeiros de café, a propor a criação de instituições a fim receber os primeiros ingênuos "libertos". Neste sentido, foram criados asilos e orfanatos de educação.

[...] Imperial Instituto Fluminense de Agricultura instituiu um "Asilo Agrícola", cujos alunos dedicar-se-iam não só aos trabalhos propriamente da lavra da terra, mas também ao fabrico de chapéus denominados do Chile e à sericultura. Em Pernambuco, no ano de 1873, é criada a Colônia Orfanológica Santa Isabel, destinada às crianças libertas. Um ano mais tarde é a vez do Piauí inaugurar o Estabelecimento Rural de São Pedro de Alcântara, no qual eram convenientemente educados os menores [...] nascidos depois da lei de 28 de setembro de 1871. Até a data prevista para a entrega, ao Estado, da primeira geração das crianças libertas, foram criadas outras três instituições: Colônia Orfanológica Cristina, no Ceará; Colônia Orfanológica de Nossa Senhora do Carmo de Itabira, em Minas Gerais; e o Asilo Agrícola Santa Isabel, no Rio de Janeiro. (DEL PRIORE, 2006, pp. 181-182).

Essa elite agrária dominava os debates em torno dos próprios privilégios em que há décadas estava constituído o país. A elite agrária que controlava a "mãos de ferro" a população escrava de forma a colocá-la submissa, sem escolhas e dependendo da boa vontade dos senhores. A sociedade brasileira impunha aos escravos condições desumanas de vida e obrigava a viverem sob a vigilância contínua. Os negros

[...] deslocavam-se pelas ruas, em sua faina diária, mas todas as suas atividades eram estritamente regulamentadas; não podiam andar à noite sem bilhete do senhor, não podiam vender nada sem as suas autorizações, não podiam servir-se de condução coletiva nem dispor livremente do próprio pecúlio (VIOTTI DA COSTA, 1998, p. 282,).

Durante o século XIX, inúmeros foram os conflitos, pois muito embora os senhores de escravos impusessem seu interesse e submetessem essas pessoas a viverem de forma desumana, mesmo assim os negros conseguiram se organizar. Uma das formas de 
organização que aconteceu nas grandes cidades foi através das confrarias, as quais reuniam pretos livres e escravos e, quando as libertações se intensificaram e os números de negros livres aumentaram, "[...] assumiram uma importância não só religiosa, como social, organizando caixas de auxílio mútuo e participando do movimento abolicionista" (VIOTTI DA COSTA, 1998, p. 282).

A religião católica era utilizada pelos senhores como antídoto para conter as insurreições e como recurso para submeter os escravos ao trabalho. Essa mediação por meio da Religião Católica mantinha o senhor resguardado como uma pessoa "suprema" a ser respeitada. Neste contexto,

[...] a religião aparecia como mediadora entre senhor e escravo: "o freio do homem impetuoso, o consolo do aflito, o alento do fraco, a esperança do desgraçado", apaziguadora do escravo; o confessor; "o conselheiro ideal do escravo" a recomendar-lhes resignação, conformismo, obediência ao senhor, pintado como um pai, a ser temido e respeitado (VIOTTI DA COSTA, 299, 1998).

Como forma de preparar a passagem da mão de obra escrava para a assalariada, a partir de 1870 alguns fazendeiros investiram em escolas a fim de garantir as necessidades de suas fazendas. Por exemplo, a:

[...] Escola de Minas de Ouro Preto (1875), as Comissões Geográficas e Geológicas do Brasil e de São Paulo (1875 e 1886), a Estação Agronômica de Campinas (1887), e uma concomitante diversificação institucional refletida numa maior especialização e profissionalização dos técnicos e cientistas (SCHWARCZ,1996 p.10).

Consideramos que as propostas de criação de escolas para os pobres, desvalidos e ingênuos discutidas nos congressos agrícolas buscavam atender aos interesses da elite agrária brasileira preocupada com a crise da mão-de-obra agravada pelo iminente fim da escravidão e visando preparar e disciplinar a mão de obra com vistas às novas relações de trabalho, de criar o novo trabalhador para a venda livre de sua força de trabalho.

\section{O Congresso Agrícola do Rio de Janeiro}

O Congresso Agrícola do Rio de Janeiro foi realizado em junho de 1878, organizado pelo então Ministro da Agricultura, Comércio e Obras Públicas, João Lins Vieira Cansanção de Sinimbu, que logo que assumiu o cargo resolveu realizar esse evento para consultar diretamente os proprietários das grandes lavouras da região sul do país compreendendo, especificamente, as províncias do Rio de Janeiro, São Paulo, Minas Gerais e Espírito Santo.

A opção do Ministro Sinimbu por essa região, excluindo a região norte e nordeste do país, deve-se ao fato dele ser contrário à substituição da mão de obra escrava pela mãode-obra livre, de origem asiática, como solução para o fim do trabalho escravo, especialmente nas províncias que vinham sofrendo com maior intensidade a necessidade dessa transformação devido à importância do café na economia do país. Havia também o interesse em se contrapor ao desenvolvimento do Partido Republicano na região Sul do país. O Ministro Sinimbu era o chefe do "[...] Partido Liberal, presidente do Clube da Reforma. Sobre ele recaía a responsabilidade de implementar as reformas preconizadas 
pelo Partido Liberal e esvaziar a propaganda republicana" (CONGRESSO AGRÍCOLA DO RIO DE JANEIRO, 1878,VI).

O Ministro Sinimbu realizou o Congresso sabendo do apoio que receberia da maioria das delegações que acreditavam que os "[...] asiáticos eram raça imoral, corrompida pelo ópio e inassimilável" (CONGRESSO AGRÍCOLA DO RIO DE JANEIRO, 1878, p.VII).

Estiveram presentes no Congresso Agrícola do Rio de Janeiro 400 delegados sendo que 56 proprietários de terras não compareceram, porém enviaram suas justificativas de ausências. A maioria dos participantes foi eleita em reuniões realizadas pelos fazendeiros nas diversas cidades envolvidas. De acordo com as assinaturas dos encontros preliminares para realização do evento, pelo menos seiscentas assinaturas foram colhidas das pessoas envolvidas, algumas pessoas foram indicadas "[...] pelas câmaras municipais ou por associações de classe. [...] mais de mil fazendeiros se envolveram de uma maneira ou de outra no Congresso" (CONGRESSO AGRÍCOLA DO RIO DE JANEIRO, 1878 p.VII). Considerando as dificuldades de comunicação, de transporte e outros problemas relativos ao distanciamento das cidades, o número de interessados no Congresso foi muito grande.

Os participantes do congresso levaram um questionário com as respostas debatidas pelos grupos que representavam. Esse questionário foi proposto pelo presidente do Congresso, o Ministro da Agricultura, Comércio e Obras ${ }^{5}$ com a finalidade de obter os posicionamentos das delegações e para apresentar ao Governo Imperial.

As necessidades mais urgentes indicadas pelo Governo Imperial aos congressistas no questionário eram as seguintes:

I- Quaes as necessidades mais urgentes e immediatas da grande lavoura?

II- E'muito sensível a falta de braços para manter, ou melhor desenvolver os actuaes estabelecimentos da grande lavoura?

III- Qual o modo mais efficaz e conveniente de suprir essa falta?

IV- Poder-se-há esperar que os ingênuos, filhos de escravas, constituíam um elemento de trabalho livre e permanente na grande propriedade? No caso contrário, quaes os meios para reorganizar o trabalho agrícola?

V- A grande lavoura sente carência de capitaes? No caso affirmativo, é devivo este facto à falta absoluta delles no paíz, ou à depressão do crédito agrícola?

VI- Qual o meio de levantar o credito agrícola? Convem crear estabelecimentos especiaes? Como fundal-os?

VII- Na lavoura têm-se introduzido melhoramentos? Quaes? Há urgência de outros? Como realizal-os? (CONGRESSO AGRÍCOLA, DO RIO DE JANEIRO, 1878, p.2)

O único ponto em que havia um consenso entre os Congressistas era a ideia da tecnologia e da educação agrícola, porém naquele momento não era considerado prioritário. Somente alguns com maior instrução defendiam essa ideia “[...] como o próprio Sinimbu, tinham convicção profunda da importância tecnológica, inclusive como fator de substituição de mão-de-obra (CONGRESSO AGRÍCOLA DO RIO DE JANEIRO, 1878, p.17).

Durante o Congresso Agrícola do Rio de Janeiro havia o consenso por parte dos Congressistas da necessidade da educação do povo, porém era uma educação monitorada pelos fazendeiros, pois a maior preocupação era com a agricultura e como formar pessoas 
que poderiam substituir os escravos. Para isso, era preciso pensar sobre a forma que essas escolas poderiam formar de acordo com os interesses desses escravocratas.

\subsection{A Educação no Congresso Agrícola do Rio de Janeiro}

O Congresso Agrícola do Rio de Janeiro deixa evidente que a maioria dos congressistas consideravam a imigração europeia como solução para substituir a mão-deobra escrava com pouco investimento, por se tratar de pessoas consideradas civilizadas. Outros congressistas diziam que a vinda dos imigrantes era preocupante, pois esses não se interessariam pelo trabalho na lavoura, como assalariados, haja vista que todos os imigrantes traziam a esperança de se tornarem proprietários e isso preocupava os fazendeiros. Por isso, os congressistas consideravam importante a criação de colônias agrícolas para educar os ingênuos, os filhos de escravas e órfãos para o trabalho. Os congressistas solicitaram a criação de escolas ao Governo Imperial, por considerarem que esta seria a melhor maneira de controlar essas pessoas e ter um contingente de mão-de-obra disponível para suprir as necessidades.

A seguir discutimos algumas manifestações e propostas dos congressistas sobre educação para os pobres, ingênuos e desvalidos , que foram apresentadas nas respostas ao questionário do Governo Imperial. O senhor Alfredo Silveira da Mota sugere a criação de um banco especial para financiar a lavoura, o incentivo à imigração, apontando a necessidade da construção de estradas de ferro e rodagem e outras intervenções:

1- As necessidades mais urgentes da lavoura são capitais e braços. 2- O modo efficaz de supprir essas duas faltas é a creação de bancos de crédito nas capitaes das províncias com caixas filiais nas comarcas ruraes, para empréstimos à lavoura a juro baixo, amortização relativa e longo prazo. 3- A immigração pela immigração. 4- Há depressão do crédito agrícola. 5- Convém decretar-se a grande naturalização sem restricções dos seus effeitos civis e políticos: a liberdade de cultos e o casamento civil facultativo. 6- A secularização dos cemiterios sob a administração das municipalidades, e o registro cilvil dos nascimentos e obitos devem ser executados. 7- Reforma das leis de locação de serviços, adoptando-se de preferencia o systema do salário. 8- Os ingenuos não podem constituir elemento de trabalho permanente. 9- Comunicação facil por meio de estradas de ferro e rodagem. 10- Redução de direitos de exportação para a principal industria nacional, e diminuição das tarifas nas estradas de ferro. 11- instrução principalmente agrícola, creando-se estabelecimentos nas comarcas ruraes. Extinção do tráfico de escravos de uma para outra província (CONGRESSO AGRÍCOLA DO RIO DE JANEIRO, 1878, p.10).

O congressista Candido Barreto de Souza Faria defende a lavoura, pois é dela que se tiram os meios de subsistência e o engrandecimento da nação. $O$ que mais aflige a lavoura é a falta de braços, a falta de capital e a falta de lei que regularize o trabalho a fim de aproveitar o trabalhador nacional. Para solucionar este problema, ele defende que os ingênuos, filhos de escravos, só "[...] virão a constituir um elemento de trabalho livre e permanente, se a lei que regular o trabalho providenciar no sentido de serem esses ingênuos educados em regime diverso do que hoje entre nós voga" (CONGRESSO AGRÍCOLA DO RIO DE JANEIRO, 1878, p.33). 
Carlos Marcondes de Toledo Lessa, representante de Barra Mansa, chama a atenção para o ensino profissionalizante gratuito e mantido pelo estado, sugerindo que os que neles estudassem já estavam fadados a um destino intelectual reduzido, não como profusão por todas as classes, não com vistas a produzir sábios afetados, mas sim homens de vida real e pratica (CONGRESSO AGRÍCOLA DO RIO DE JANEIRO,1978, p.35). Ele cita como exemplo a América do Norte, onde o ensino profissional e

[...] subministrado gratuitamente em todos os Estados, contudo se tem entendido que por si só elle não é sufficiente, porque na grande classe dos agricultores existentes há muitos que não tiveram a fortuna de freqüentar esses institutos de data mais recente, que o exercício de sua profissão toma-lhes inteiramente o tempo (CONGRESSO AGRÍCOLA DO RIO DE JANEIRO,1978, p.35).

Cesario N. de A. M. Magalhães Junior, representante Porto Feliz e Capivary-SP, relata que as necessidades da lavoura em sua localidade são as mesmas que em todas as outras: capital, braços e instrução. Uma de suas preocupações era a educação dos ingênuos e dos órfãos. Reconhece que estes receberam, até então, um trato minimizado por parte do Estado e abandonados pelos seus proprietários, só resta educá-los em escolas agrícolas. Solicita a criação de escolas para formar professores em uma fazenda modelo, para que os alunos aprendessem no exercício prático e onde os lavradores possam ir ver os progressos realizados. Solicitou a criação de escolas municipais, onde esses professores ensinem a teoria; e fazendas-escolas em que os alunos possam praticar o que aprenderam. Atribui às províncias a responsabilidade de custear essas escolas através de alguns impostos para a criação de institutos normais e, para os municípios, a responsabilidade de prover gratuitamente toda instrução elementar e também as escolas agrícolas primárias. (CONGRESSO AGRÍCOLA DO RIO DE JANEIRO, 1978)

$\mathrm{Na}$ resposta ao questionário do congresso encaminhada pelo Sr. Irenêo Francisco de Souza e Silva, comerciante e agricultor de Porto Alegre, Província de São Pedro do Rio Grande do Sul6, manifesta que "a condição essencial a resolver é a instrucção agrícola nas escolas primárias, por meio de cursos apropriados. Os ingênuos, filhos de escravas, serão sem duvida para o futuro uma forte alavanca a agricultura, si os obrigarmos à educação agrícola especialmente.” (CONGRESSO AGRÍCOLA DO RIO DE JANEIRO,1978, p. 41)

O representante de Niterói-Rio de Janeiro, o Sr. Joaquim Antonio de Carvalho Agra observa que não se pode esperar que os ingênuos, filhos de escravas, sejam considerados adequados para o trabalho livre e permanente na grande propriedade, para o que

[...] concorrem muitas circunmstancias; e, além disso, o numero desses ingênuos torna-se limitadíssimo, em $1 \circ$ logar pela morte de muitos delles; em $2 \circ$ pelas alforrias das mãis, das quaes não se podem separar; em $3 \circ$ pelo grande lapso de tempo a esperar pelos seus serviços; em $4 \circ$ pela educação licenciosa e animada por essa liberdade que os autoriza a não sujeição ao trabalho; e finalmente por muitas outras causas que para isso concorrem e seria longo relatar (CONGRESSO AGRÍCOLA DO RIO DE JANEIRO,1878, p.42).

Para os Lavradores de Lage do Mauriahé, a necessidade mais urgente era a criação de prédios apropriados para a organização de uma escola de prática de agricultura para atender os ingênuos até atingir a maioridade de vinte e um anos, após este período lhes seria dado o direito de se matricular no grupo de lavradores. As escolas práticas também receberiam os rapazes de dez anos de idade para praticar até que alcancem a idade de vinte 
um anos e é claro poder fazer parte do corpo de lavradores, tudo isso sem nenhum ônus para o estabelecimento.

Laurindo José de Almeida defende o modelo de escolas Norte Americano de Massachusetts nos Estados Unidos. Acreditava ele que este tipo de estudo profissional em institutos agrícolas seria muito bem aceito pelos lavradores, dado que alguns filhos de fazendeiros de Juiz de Fora já haviam retornado dos estudos que foram procurar neste país

O representante da fazenda Serra Bonita, Manoel Furtado da Silva Leite se declarou contrário à Lei do Ventre Livre, que para ele foi um golpe no país, que não estava preparado para isso. Ele acreditava que era um golpe tão terrível, que

[...] armando o braço escravo contra o seu senhor... esta lei abysmou a nação; creou milhares de victimas,e numerosas difficuldades impoz aos agricultores, já relativas a matriculas, baixas, averbações e muitas, já e sobretudo aquellas que se referem aos ingênuos; baixas dos que morrem, despesas que se fazem com viagens para tal fim CONGRESSO AGRÍCOLA DO RIO DE JANEIRO,1878, p.47).

Os lavradores de Baependy também defenderam a proposta de oferta de educação pública, através de uma

[...] solida educação moral, religiosa, civica, intellectual e profissional, por meio da qual não só a lavoura com seus recursos actuaes de braços e capitaes, conseguirá a dupla vantagem de augmentar melhorando seus productos, como ainda adquirirá milhões de operarios ociosos no paiz, uns, os camponezes, em quasi barbaria, outros, os índios, em completa barbaria, e que neste triste estado pouco ou nada trabalham, porque habituaram-se ao pouco e mesmo à miseria, e porque imersos na ignorancia, não consideram o trabalho sob seu verdadeiro aspecto - como uma lei da natureza humana e uma necessidade social (CONGRESSO AGRÍCOLA DO RIO DE JANEIRO,1878, p.54 ).

Os lavradores de Baependy atribuem ao Estado a responsabilidade com a educação, através da intervenção da trindade política: Município, Província e Estado, não só para custear esse ensino como também para vigiar o funcionamento.

Ao Estado caberia a abertura de escolas primárias em todas as freguesias, capelas, pequenos lugarejos povoados, onde não houvesse escola principalmente as práticas especiais para preparar agricultores. A educação pública deveria ser oferecida a todos os menores, aproximadamente em torno de 1.583 .705 crianças de idade escolar, que estavam sem escolas, fato que chamou atenção para educação de adultos analfabetos que certamente era um número bem maior. Defendeu que era necessário organizar o ensino primário em todo "país" para isso era "[...] preciso organizar um numeroso e habilitado professorado, e portanto creear escolas normaes em quantidade sufficiente, bem como melhorar a condição dos professores públicos" (CONGRESSO AGRÍCOLA DO RIO DE JANEIRO, 1878, p.57).

Para este grupo da sociedade, a necessidade da criação da escola normal está atrelada ao processo de reformulação das já existentes ou da criação de outras que contemplem o novo conteúdo exigido pela realidade vivida pela sociedade brasileira. Quando propõe a criação de escolas normais está se referindo às escolas preparadoras de professores para atuar nas escolas agrícolas.

Naquele período, as escolas normais eram vistas como estabelecimentos escolares que produziam poucos frutos para o ensino primário no país: 
[...] isto se deve, sobretudo a tentativas mal dirigidas, a uma certa inexperiência prática que a um defeito inerente à instituição. Não se deve duvidar que uma escola normal bem organizada, provida de todos os elementos necessários, dirigida por um homem capaz, confiada a professores instruídos e inteligentes, submetida a sábios regulamentos não possa preparar os jovens de uma maneira conveniente para torná-los instrutores capazes. As escolas que tinham necessidade de professores adjuntos poderiam imediatamente recrutá-los na Escola Normal; seria um estágio útil para aqueles que seriam escolhidos. Este estabelecimento poderia, em poucos anos, tornar-se um viveiro de institutores, não só para a capital, mas também para todas as províncias do império, que teriam o direito de enviar para lá seus alunos, mediante dotação proporcional, prevista no orçamento particular de instrução pública. Há aí uma idéia prática cuja realização completa seria um benefício para o país (ALMEIDA, 1989, p.10).

A Companhia União dos Lavradores defende a ideia da necessidade de ensinamentos dos deveres morais do homem para com Deus, a família, a sociedade e o país. Só poderão ser professores ou adjuntos das escolas primárias os brasileiros e brasileiras de bons costumes e especialmente habilitados nas escolas normais, todos os bacharéis e doutores formados em qualquer estabelecimento público de ensino superior, e os clérigos de ordens sacras. A fiscalização das escolas e do imposto escolar deverá ficar a cargo de cada província, através de uma diretoria formada de pessoas que seriam responsáveis pela instrução agrícola, teórica e prática sem a qual, por mais que espalhem os instrumentos de produção não poderão ser bem aproveitados em um país de analfabetos (CONGRESSO AGRÍCOLA DO RIO DE JANEIRO, 1878).

Para a garantia da riqueza e da produtividade da lavoura, os agricultores e grandes fazendeiros defendiam ser preciso melhorar a relação com os conhecimentos científicos oferecidos nas escolas existentes. Neste sentido, o ministro da agricultura em seu discurso no Congresso Agrícola afirmou que

Na situação actual de nossa grande lavoura, quando uma profunda evolução social se opéra; quando completamente se transformam as condições do trabalho rural; quando paizes analogos ao nosso, com produções similares, procuram progredir por todos os meios, mediante machinas e processos mais aperfeiçoados, que as sciencias - a chimica, a phisica e a mecanica - em suas variadas aplicações, tem posto ao serviço da industria agricola, conservamo-nos estacionarios no meio desse grande movimento, sem ao menos empenharmos os esforços a nosso alcance para evitar que enfraqueçam ou se estanquem as fontes de produção nacional, seria, senhores, permitti-me dizel-o, não sómente um erro, mas um grave crime, perante o tribunal da geração vindoura. A marcha da sociedade está, porém, sujeita a leis naturaes, que não podem ser alteradas sómente pela vontade dos homens; e, por em quanto, nas condições atuais do paiz, é força reconhecer, a grande propriedade tem sido, e continuará ainda por muitos annos a ser, a poderosa alavanca do nosso progresso em suas variadas manifestações - progresso moral, social, economico e politico (CONGRESSO AGRICOLA DO RIO DE JANEIRO, 1878. pp. 125 e 126).

A criação de escolas agrícolas foi defendida também pelos lavradores do Rio de Janeiro, Minas Gerais e Espírito Santo como forma de desenvolver as futuras gerações que deverão atender a lavoura. J. C. de M. Monteiro de Barros trouxe para o Congresso 
Agrícola a defesa da Instrução primária obrigatória em um documento com 24 artigos, todos bem distribuídos como forma de visualizar a escola pública que os fazendeiros estavam pensando para as crianças órfãos e filhos de escravos: uma escola pública em cada paróquia do Império, ao menos uma escola pública de instrução primária para meninos, se sobrar dinheiro dos impostos seriam criadas escolas para meninas.

João Baptista Braziel de Rezende - Rio de Janeiro, defende o apoio à escola onde se ensine o trabalho agrícola. Ele acreditava que se deve considerar que estamos em circunstâncias especiais em uma época transitória entre o sistema "[...] de lavoura própria para mattas virgens, propria para o estado selvagem, e o systema scientifico, pelo menos a necessidade do emprego de instrumentos que não sabemos manejar" (CONGRESSO AGRÍCOLA DO RIO DE JANEIRO,1878, p. 140).

Acentua o mesmo congressista, que em um país completamente agrícola como o Brasil, é inconcebível que não exista, custeada pelo Governo, uma escola onde se ensine agricultura. Os agricultores reconhecem a necessidade de escolas públicas para formação mão-de-obra, que prepare para executar as técnicas e o manejo na agricultura.

Outros objetivos foram apresentados pelos congressistas, porém observando que as mais benéficas intenções do governo não podem ser eficazmente realizadas sem o concurso da classe a que esse intuito mais interessa. Por isso foi promovida uma reunião para se estabelecer um nexo entre a grande lavoura, que se sente ameaçada, e o Governo que tem interesse em colaborar. A respeito, assim se manifesta o Sr. Francisco de Assis Pereira de Andrade, de Ouro Fino, Rio de Janeiro.

Não avesso à escolas agrícolas, ao ensino profissional, ainda lembrado pela commissão de S. Paulo; mas não tem isto oportunidade, porque, precisando a lavoura de capitaes, seria mais um sorvedouro desses poucos capitaes que ella e o thesouro têm, porque, em ultima analyse não vai buscar dinheiro em outra parte sinão mesmo na lavoura (CONGRESSO AGRÍCOLA DO RIO DE JANEIRO,1878, p.150).

Diante da necessidade de formar pessoas qualificadas para trabalhar na lavoura, o Conego Joaquim Camilio de Brito, de Mar de Hespanha, Minas Gerais, defende a criação de fazenda escola mantida pelo governo.

Nessas fazendas escolas serão recebidos orphãos desvalidos, menores que dos pais não recebam educação e emprego útil, e os ingênuos cedidos gratuitamente pelos senhores de suas mães ou pelo Estado. Não nos devemos levar somente pelo sentimento; o verdadeiro patriotismo deve consistir naquillo que é real e racional: ao pai que for negligente tire-se o filho para ser educado e tornar-se bom e útil cidadão. 1 (CONGRESSO AGRICOLA DO RIO DE JANEIRO,1878, p.153).

Seria a criação de instrução agrícola através da formação de colônias agrícolas em diferentes partes do país, porém seguindo os exemplos dos países considerados desenvolvidos

Essas colônias, com uma boa administração e um centro industrial bem organizado, não serviria apenas de escolas práticas para instruir a infância, mas também seriam aproveitadas para núcleos dos colonos europeus que mais tarde seriam aqueles que iriam fazer a propaganda da colonização para o nosso país. Desta forma, o fazendeiro poderia se servir deste modelo para que ele próprio conhecesse praticamente o modo de tornar-se, ele próprio, o industrial do estabelecimento dos colonos,

[...] ou dos foreiros, ou dos lavradores livres, que de futuro devem necessariamente povoar os terrenos das grandes fazendas de cultura,

Revista HISTEDBR On-line, Campinas, $n^{\circ}$ 52, p. 54-74, set2013-ISSN: 1676-2584 62 
ficando deste modo estabelecido o grande principio da subdivisão do trabalho e da grande propriedade (CONGRESSO AGRÍCOLA DO RIO DE JANEIRO, 1878, p.153)

Os grandes fazendeiros não conseguiam esconder suas ideias revelando no Congresso Agrícola suas "verdadeiras" concepções acerca da realidade brasileira através da instrução primária que gostariam que fosse oferecida aos trabalhadores, servindo de excelente contrapondo às ideias liberais e fornecendo dados que revelam o pensamento reformista do final do século XIX (AITA, 2006).

Na memória apresentada ao Ministério da Agricultura, Comércio e Obras Públicas, o Marechal de Campo Sr. Henrique de Beaurepaire Rohan defende que os ingênuos, os filhos de escravos originariamente livres, deveriam ser tratados como um elemento de trabalho, que se fossem convenientemente educados tornar-se-iam produtivos para a sociedade. Considera a educação como aquela que salvo o indispensável estudo das primeiras letras, tem por fim iniciar e acostumar os alunos ao trabalho produtivo.

Neste sentido não posso senão applaudir a idéia da escola agrícola do
Jardim Botanico, debaixo das vistas do Sr. Visconde do Bom-Retiro,
assim como da colônia orphanologica creada na Villa da Estrela pelo Sr.
Dr. Gonçalo do Faro, e outras mais que, apezar de não se occuparem do
ensino agrícola, nem por isso deixam de ser uteis no sentido de promover
a educação industrial das crianças desvalidas (CONGRESSO
AGRICOLA DO RIO DE JANEIRO,1878, p.249).

Assim, acreditava-se que a educação dos ingênuos e demais homens livres que deveria ser oferecida em todas as comarcas produziriam [...] dentro de poucos anos, realizado uma benéfica transformação das classes indolentes em operários uteis (CONGRESSO AGRICOLA DO RIO DE JANEIRO, 1878, p.250).

Os fazendeiros tinham clareza que para resolver o problema da sua indústria em ascensão era preciso substituir o trabalho escravo pelo trabalho livre, por isso a defesa de ensinar os ingênuos e escravos livres as operações da lavoura, escolha das terras apropriadas a certas e determinadas "[...] culturas; a semeação, transplantação, pódas, enxertias, colheitas, melhoramento do solo por meio de adubos, estrumes, irrigação, drenagem, etc." (CONGRESSO AGRÍCOLA DO RIO DE JANEIRO, 1878, p.251).

A proposta firmada pelos congressistas era a instituição do ensino primário obrigatório pelo qual se lecionariam basicamente os elementos de educação agrícola e, de preferência, em escolas fazendas onde as crianças deveriam praticar o ofício, porém estas vantagens com o trabalho associado seriam o "[...] único meio de evitar o salário, à guisa do que praticam os pequenos lavradores em algumas províncias do Brazil" (CONGRESSO AGRICOLA DO RIO DE JANEIRO,1878, p.251).

Os ingênuos, para que pudessem ser homens moralizados, dignos cidadãos de um país civilizado, deveriam receber educação longe dos cativos. "Se os fillhos das escravas forem criados à laia de captivos, podemos affirmar que, quando chegarem à época de sua definitiva libertação, estarão tão embrutecidos como os seus progenitores" (CONGRESSO AGRICOLA DO RIO DE JANEIRO,1878, p.251).

Para os representantes da elite agrária brasileira, a escola pública e obrigatória, ou a escola como sendo de direito de todos, vem como forma de erradicação da ignorância do povo, de "[...] preparação do trabalhador para a venda livre de sua força de trabalho e os ingênuos, deveriam ser treinados para [...] disciplinar a mão de obra com vistas às novas relações de trabalho"(SCHELBAUER, 1998 p.52). 
Para isso não se defendia uma escola com estrutura necessária diziam os congressistas nada [...] de directores, vice - diretores, ajudantes, secretários, almoxarifes e outros tantos empregos, sem os quaes temos a balda de pensar que não há instituição possível (CONGRESSO AGRICOLA DO RIO DE JANEIRO,1878, p.252).

Em várias partes do documento do Congresso Agrícola no Rio de Janeiro aparece como necessidade dos fazendeiros a utilização das máquinas na lavoura e junto o estudo dos tipos de solo, visando a maior produtividade. Defendiam os fazendeiros que esses conhecimentos deveriam ser "ensinados" aos trabalhadores por eles preparados e selecionados, como forma de sanar a mudança de mão-de-obra e também de livrar esse povo da indolência, era o que incomodava os Congressistas do Rio de Janeiro.

Nos discursos, os congressistas deixavam transparecer a resistência dos fazendeiros para com o povo, quando não aceitavam, chamando-os de indolentes. Neste sentido, assim se manifesta o Sr. Joaquim José Alvares dos Santos Silva, de Leopoldina, Minas Gerais.

O nosso povo é de um natural indolente e não se presta geralmente ao serviço da agricultura. Os operários nacionaes entendem que nesse serviço se degradam e não o querem prestar, preferindo comer la no seu canto um pedaço de rapadura e beber uma chicara de café, a adquirir por meio do trabalho agrícola nas fazendas os meios de alimentarem-se melhor em suas choupanas (CONGRESSO AGRICOLA DO RIO DE JANEIRO,1878, p.155).

O homem "livre" deveria ter apenas como mirante, o necessário para sua subsistência e não uma produção capitalista, com as necessidades de duração da jornada de trabalho, defendida pelos fazendeiros no Congresso do Rio de Janeiro.

Todo o processo de produção do país baseado no trabalho escravo, o qual perdurou por quase quatro séculos, estava esgotando-se, porém de forma ladina e sorrateira. A elite dirigente, conservadora e proprietária de grandes latifúndios, por meio do modelo de produção monocultora para a exportação, com predominância da região sudeste com o café, buscou atender somente aos seus interesses.

A instrução primária no ensino agrícola era difundida como a instrução popular necessária destinada a toda a população livre. A escola primária pretendia constituir um espaço de integração e inclusão social, recebendo as crianças provenientes das famílias pobres para prepará-las para a aquisição futura de uma instrução profissional. Por outro lado, ao limitar ao nível primário a "[...] dívida sagrada e restrita" do Estado, a escola também buscava excluir, criando e recriando hierarquias, diferenciando as crianças pobres daquelas pertencentes à "boa sociedade" (CONGRESSO AGRÍCOLA DO RIO DE JANEIRO, 1878, p.155).

O Congresso Agrícola do Rio de Janeiro encerrou com a proposta de incutir no povo brasileiro, principalmente aos pobres, nacionais e estrangeiros, uma formação de amor ao trabalho, que não forneça apenas as habilidades e "[...] técnicas indispensáveis ao melhoramento dos cultivos, mas, incutir-lhes o dever e o amor ao trabalho, atributos morais indispensáveis e sem os quais permaneceriam alcunhados como subhumanos" (CONGRESSO AGRÍCOLA DO RIO DE JANEIRO, 1878, p.155). 


\section{Congresso Agrícola do Recife}

O Congresso Agrícola do Recife (1878) foi organizado pela antiga Sociedade Auxiliadora de Agricultura de Pernambuco em protesto ao Congresso ocorrido em junho do mesmo ano, no Rio de Janeiro, convocado pelo Governo Imperial. O decreto imperial autorizou a participação apenas das províncias do Rio de Janeiro, São Paulo, Minas Gerais e Espírito Santo, restringindo a participação das demais províncias do país. Eram evidentes as intenções do Governo Imperial ao convocar apenas alguns interessados em analisar a situação da "Grande Lavoura", que no entender dos congressistas recifenses, os reais objetivos eram discutir os problemas relativos à cafeicultura brasileira. (PERRUCI, 1978, p. XVI).

Os congressistas que representavam a elite agrária nordestina e nortista apresentaram muitas queixas e protestos por se considerar abandonados e isolados frente aos produtores rurais do sul do país. Ao deixar os nordestinos de fora, se constata o quanto a região foi relegada a segundo plano diante do cenário econômico que se definia na época. Diversas críticas foram feitas sobre a forma como o governo imperial excluía as regiões mais pobres e favorecia a região Sudeste, que tinha um poder econômico superior ao do restante do País. Por outro lado, havia também a esperança do Congresso do Recife chamar a atenção das autoridades da Corte Imperial para os problemas que estavam enfrentando.

O Congresso Agrícola do Recife iniciou em 06 de outubro de 1878 sob a presidência do Dr. Manoel do Nascimento Machado Portella, com a presença de representantes das províncias de Pernambuco, Alagoas, Paraíba, Rio Grande do Norte, Sergipe e Piauí. O Ceará não conseguiu enviar nenhum representante. Também participaram do Congresso muitas pessoas engajadas no movimento em defesa dos fazendeiros e também uma comissão da Associação Comercial Beneficente e da Associação Comercial Agrícola. O Congresso do Recife teve um total de 113 participantes.

Com as mesmas preocupações do Congresso do Rio de Janeiro com a questão da mão de obra, dos capitais para financiamento da lavoura e os efeitos da Lei do Ventre Livre de 1871, os congressistas de Recife assim manifestaram em relação à educação.

\subsection{A Educação no Congresso Agrícola do Recife}

No congresso defendia-se o ensino primário para os menos favorecidos, porém para os que apresentassem um pouco mais de capacidade e habilidade deveriam ser encaminhados para a educação agrícola. Com isso, tirava-se proveito da primeira infância dessas crianças, com o intuito de levar todas as crianças nascidas libertas a trabalhar na agricultura.

Para o Sr. João Fernandes Lopes devia-se defender a criação de colônias orfeônicas para os ingênuos, "como a Izabel, onde a par da instrucção obrigatória elles recebam noções de agricultura; pois que só assim poderão vir a ser bons agricultores (CONGRESSO AGRÍCOLA, 1878, p.136).

A educação dos ingênuos era pensada para que se pudesse oferecer a esses meninos, nas escolas agrícolas, uma educação profissional, com uma formação para atender à agricultura das fazendas da região, conforme o Sr. Vicente Cysneiros.

[...] era não somente desejável, como necessidade urgente, visto estar próxima a hora em que deve principiar a entrega delles ao Estado; que este era o único meio de aproveital-os a beneficio da lavoura, pois os que ficassem nos engenhos até 21 annos os abandorariam logo que pudessem

Revista HISTEDBR On-line, Campinas, $n^{o}$ 52, p. 54-74, set2013 - ISSN: 1676-2584 65 
fazel-o. Accrescentou, que muito applaudia a Idea de uma emissão especial de papel moeda a favor da Agricultura do Norte; que o Governo não podia negal-a, porque já favorecera a Lavoura do Sul com uma emissão especial de 25 mil contos (CONGRESSO AGRÍCOLA DO RECIFE, 1878, p.139).

Nos discursos dos fazendeiros ficava registrado o quanto queriam que os ingênuos permanecessem como "semi-escravos" nas lavouras onde suas mães trabalhavam. E agora os filhos libertos seriam trabalhadores livres, superiores aos que permaneciam escravos, porém ainda dependentes do senhor.

Para os congressistas, era preciso fundar colônias agrícolas, a exemplo da Colônia Isabel, para recolher e educar os ingênuos, que eram os libertos, conforme os interesses dos fazendeiros. Os ingênuos que eram considerados

[...] não somente útil, mas de urgência, pois 1879 nos bate a porta e de 28 de Setembro de 1879 em diante hão afluir os taes ingênuos, sem o Governo estar prompto para accommodal-os: sem contar, que este é o único meio de utilizar para a produção agrícola parte daquella geração, pois, como mui acertadamente disse o Sr. Barão de Muribeca, é preciso não conhecer a natureza humana para crer, que os criados até 21 annos pelos senhores de suas mães ficarão no lugar onde ellas forem captivas e occupando-se na lavoura da canna, que lhes recordaria a meia escravidão em que permanecem até então (CONGRESSO AGRÍCOLA DO RECIFE, 1878, p.151).

A proposta de criação de escolas agrícolas como salvação para preparar os ingênuos, passava a ser considerada também de serventia para os filhos dos agricultores, como se manifesta o Comendador Antonio Valentim da Silva Barroca no memorial submetido ao congresso.

Senti mais de perto a molestia desta classe, e directamente avaliei a falta que todos sentimos de escolas agrícolas, em que os filhos dos agricultores possam receber a instrucção technica profissional, que em paizes menos agrícolas não falta. É realmente doloroso, e até inacreditável, que neste paiz de tão vasta extensão territorial, de solo tão ubérrimo, e de tão ricas producções, não exista uma só escola agrícola! E todavia é uma triste verdade! D' ahi vem não só ignorância que nos esterelisa, mas também o abandono em que vivemos, por inópia de exacta comprehensão de nossos diretos e deveres (CONGRESSO AGRÍCOLA DO RECIFE, 1878, p. 162).

O Comendador Antonio Valentim da Silva Barroca lamenta que nem todos defendiam a necessidade de instrução por considerar que os trabalhadores da agricultura não necessitavam de instrução.

Não admira que assim se exprimam alguns litteratos, quando homens da própria classe julgam, que para ser bom agricultor basta saber pegar na rabiça do arado; e outros até preconisan a enxada e a torina dos séculos passados! (CONGRESSO AGRÍCOLA DO RECIFE, 1878, p. 172).

Com a falta de instrução profissional em todo o Império, os agricultores que desejavam preparar melhor seus filhos o faziam fora do País e a grande maioria dos filhos dos fazendeiros ricos escolhiam estudar nos Estados Unidos. Essa realidade se dava com muita frequência com os fazendeiros de café. Já os agricultores do Nordeste reclamavam 
que, devido a cana-de-açúcar e o algodão serem pouco rendosos naquele momento, não podiam ir tão longe para se especializar.

Os agricultores em geral acreditavam que para o desenvolvimento da lavoura era preciso apenas dinheiro. Porém, devido às condições de atraso em que se encontrava a lavoura do Nordeste, havia a aposta na instrução como estratégia para superar as dificuldades, mas uma instrução aligeirada, sem muitos investimentos e para atender apenas alguns, selecionados por eles. O memorial enviado pelo Sr. Dr. Olintho José Meira, agricultor da província do Rio Grande do Norte expressa bem essas ideias.

Penso que para este fim devem ser creadas escolas apropriadas; mas, para que o optimo não torne inimigo do bom, também penso que não devem ser exigidas com demasia, porém apenas quantas forem indispensáveis. A creação de uma escola em cada município, como tem alguns opinado, considero-a nimiamente apparatosa. Nesta província, por exemplo, entendo que uma é sufficiente: não queiramos viajar ao redor do mundo em oitenta dias. Nessas escolas têm de se formar profissionaes, que um pouco mais tarde serão chamados à dirigir os estabelecimentos agrícolas; e se o numero delles for insufficiente, serão creadas novas escolas, já então sob melhores auspícios (CONGRESSO AGRÍCOLA DO RECIFE, 1878, p. 199).

O aparente interesse na instrução por parte dos agricultores se deu devido à necessidade de se buscar fora do País orientações sobre como conduzir a lavoura de forma técnica e lucrativa. Desejava-se com isso:

Adaptar melhor as differentes culturas ao solo, que lhes é próprio, para poder entrar na cultura intensiva e no aperfeiçoamento do fabrico, para dirigir emfin os apparelhos e machinas nas diversas operações de uma e outra industria, rural e fabril (CONGRESSO AGRÍCOLA DO RECIFE, 1878, p. 200).

Os grandes fazendeiros do Nordeste reclamavam da escassez de mão-de-obra escrava da mesma forma que os da região Sudeste. O reclamo maior estava em que os fazendeiros do Nordeste haviam vendido seus escravos para atender a região Sudeste e, com a proibição de trazer escravos para o País, queixavam-se da falta de ajuda do governo imperial.

Entendiam que a mão-de-obra considerada livre estava despreparada para atender às fazendas de engenhos de açúcar. Assim, a criação dos cursos de ensino profissionalizante era vista pelos grandes fazendeiros do Nordeste como a solução para a falta de mão-de-obra, para atender os interesses da agroindústria, visto que os trabalhadores livres que estavam sem ocupação seriam encaminhados ao mundo do trabalho assalariado.

Assim se manifesta o Sr. Francisco Maria Duprat na resposta ao questionário do congresso, no quesito sobre a falta de braços para manter ou melhorar e desenvolver a lavoura, com a observação que

Se os braços livres, que superabundam vadios e ociosos nos cercados dos grandes engenhos de assucar, estivessem pelo contrario a trabalhar, a grande lavoura não se resentiria de falta de braços; mas antes de se effectuarem estas mudanças, antes de ser adoptado este importante melhoramento, comer-seha muito pirão: para isto se precisa [...] de uma reconstrucção social pacífica. Entretanto, poder-se-hia ter realisado 
exemplos destes melhoramentos, se tivesse realisado a escola agrícola normal [...] (CONGRESSO AGRÍCOLA DO RECIFE, 1878, p. 223).

Concluindo suas observações, o Sr. Francisco Maria Duprat manifesta o desejo do governo promover mais a instrução agrícola, com a criação de escolas

[...] especiaes e ainda concurrentemente com ellas, póde e deve ser dada por meio de publicações periódicas que tratem especialmente dos interesses da agricultura, não teria em tanto menospreso o sacrifício de tempo e de dinheiro, que tenho feito para manter o Brasil Agricola, no louvável intuito de promover os melhoramentos da primeira e mais importante industria do império do Brasil, que é minha segunda pátria, e a pátria de minha mulher, de meus filhos e netos (CONGRESSO AGRÍCOLA DO RECIFE, 1878, p. 229).

Uma das reivindicações feitas no Congresso Agrícola do Recife era a criação de escolas orfanológicas, que ajudariam a região a estar em iguais condições que a região Sudeste. Elas deveriam ser criadas em

[...] Colonias orphanologicas, uma pelo menos em cada municipio, quer para a cultura da canna, quer para a cultura do cafeeiro, mantidas as ditas colônias pelo governo durante seis anos, para a cultura da canna e durante doze para do café; findos os quaes, o governo nehuma despeza fará com ditos estabelecimentos, que ficarão a cargo dos proprietários, tendo sómente o governo a fiscalisação; creando-se assim focos de trabalhadores em vez de lançar-se ao meio da rua mais desfavorecidos da fortuna, que iriam augmentar o numero de assasinos e ladrões (CONGRESSO AGRÍCOLA DO RECIFE, 1878, p. 230 ).

Os congressistas solicitaram que houvesse mudanças na Lei 76 , que regulava a instrução da época, ampliando o número de disciplinas, como apresenta o Dr. Manoel Balthazar Pereira Diegues Junior.

Há uma escola normal, um lyceo, algumas aulas de latim e francez avulsas. Nessas escolas predominam os velhos systemas, e o ensino abstracto continúa a ter seu império, mantendo a estação da esterilidade. Convém mudar o curso do ensino; é necessário que, a par da educação intellectual, a escola ministre a educação social; a par da cultura ou ornato da intelligencia, a escola proporcione o desenvolvimento das forças e suas applicações no trabalho, assim como a perfeição da moral (CONGRESSO AGRÍCOLA DO RECIFE, 1878, p. 261).

Esse congressista defende a ideia de que a instrução pública fique a cargo dos municípios ou de conselho formado por famílias, e ainda ao município caberia cuidar da instrução secundária e superior. Considera que a inspeção se faria de forma a regular toda a instrução do município, coordenada, claro, pelos interesses dos escravocratas, de maneira que esta expansão

[...] ressultará que a instruçção primária será dada ao sabor das necessidades locaes e a instruçção secundaria e superior será difundida, crecendo o numero dos bacharelados em todos os ramos das sciencias; e o professorado, em vez de sahir dessa phalange de ignorantes, e homens sem aspiração, que as mais das vezes, com algumas honrosas excepções, occupam o magistério, sahira d'esse foco mais amplo do saber. Para que o magistério seja competente, todos os gêneros de recursos deve empenhar a autoridade; emquanto não tomem raízes essas novas 
instituições, muito convem, em poucas escolas modelos, mesmo em uma em cada província, preparar professores que vão fundar os melhores systemas (CONGRESSO AGRÍCOLA DO RECIFE, 1878, p. 262).

Para o congressista Joaquim Alvares dos Santos Souza a solução para o desenvolvimento do Nordeste estava na criação de escolas de instrução pública primária que preparassem para a indústria, nem que para isso fossem criadas leis que coibissem pessoas que estivessem na vagabundagem e na ociosidade e fosse

[...] imposto um regimen policial severo, á que deverão estar sujeitos todos os indivíduos sem arte, sem officio; e ficai certo que correrão esses braços inactivos aos doces prazeres da colheita, para obterem uma posição d'alguma confortabilidade (CONGRESSO AGRÍCOLA DO RECIFE, 1878, p. 291).

Solicitava que fossem criadas escolas de colônias agrícolas ${ }^{7}$ de trabalho mútuo, no sistema alemão, para que nelas as pessoas fossem educadas para o trabalho, de forma que essas colônias teriam o papel de suprir a demanda de mão-de-obra escrava que estava em falta, principalmente no Nordeste, por isso a preocupação em educar

[...] os filhos da mulher escrava, os orphãos desvalidos, os filhos dos indigentes, os dos proletarios, que actualmente pobres infantes, innocentes creaturas, vagueiam nas ruas e estradas publicas, e teremos activos e aproveitáveis braços para a grande e pequena lavoura e caminharemos, senhores, de frente erguida para ocupar-mos as avançadas da civilização [...]!! Desapparecerá, ficai certos Srs. do Congresso, a preguiça, a indolencia, irmã congênere do luxo, do crime e da perdição! (CONGRESSO AGRÍCOLA DO RECIFE, 1878, p. 291).

A camada mais pobre da população brasileira, composta predominantemente de negros, se deixava iludir e se agregava aos objetivos desses dominadores. Até crianças eram exploradas. Para "[...] guiar carroças eram aceitas para o trabalho. Pedreiros, canteiros, serventes eram ofícios frequentemente requisitados para os serviços das estradas e caminhos" (MOURA, 1998, p. 83). Muitos foram ajudar os fazendeiros a enriquecer, porém, sem direitos, eram fadados a viver como mendigos longe dos direitos mínimos. $\mathrm{E}$ como forma de cercear essa população pobre e desamparada de direitos criavam-se leis como forma de defesa dos grandes fazendeiros.

O professor João José Rodrigues do Alto São Francisco solicita que o

[...] governo torne effectivo o ensino obrigatório, crie leis que impeçam a vadiação e vagabundagem, e facilite aos brasileiros o acharem accupação. $\mathrm{E}$, querendo fazer todas essas cousas, não se esqueça de que a maioria do nosso povo é ainda muito rotineira, só faz o que vê fazer, quase que só caminha à empurrões (CONGRESSO AGRÍCOLA DO RECIFE, 1878, 373).

A escola pública para as crianças, jovens e adultos das camadas pobres, livres, nacionais e estrangeiras, e libertas no período imperial, não foi um elemento primordial para a manutenção e reprodução sociais no século XIX, embora estivesse presente nos projetos de reforma dos governantes das províncias, quando era de interesse. As escolas, quando eram criadas, eram em quantidade e qualidade bastante limitadas, destinadas aos poucos indivíduos "[...] da minoria dominante, sendo um mero ornamento e estendendo-se, quando muito, à camada média, a quem conferia status" (NASCIMENTO, 2004, p. 42). 
Diante dos poucos esforços em uma sociedade senhoril e escravista, não existia o interesse em efetivar a escola pública para todos e muito menos para os negros, uma vez que estes não cumpriam "função relevante" na situação de libertos. A base do escravismo é econômica e ela condiciona todos os outros fatores sociais, políticos e culturais. Com isso posto, o sistema escravista orquestrava o desenvolvimento do país, direcionando para onde lhe interessava a população mais pobre a receber o mínimo do mínimo. "Em um [...] país com atrasos históricos, sociais, políticos e culturais imensos [...] o sistema escravista determinou em toda a extensão geográfica do Brasil o seu ritmo de desenvolvimento e o conteúdo fundamental das relações interétnicas" (MOURA, 1983,15)

Os escravos, analfabetos tratados como animais e impedidos de frequentar escolas públicas, não tinham voz ou meios para protestar. Quem então podia exercer pressão suficiente para que seus direitos fossem ouvidos? Apenas a "[...] camada média da população, que por meio da escolarização pretendia participar dos privilégios da classe senhorial, que havia apoiado" (NASCIMENTO, 2004, p. 42).

Ao longo de quase todo o século XIX, o país teve um desenvolvimento muito precário, com uma economia baseada na continuidade da escravidão dos homens negros, mantidos como força de trabalho na produção agrícola em latifúndios, sendo que a incipiente indústria se mantinha em relativo imobilismo devido à preferência pela importação dos artigos manufaturados bem como pela adoção do modelo agro-exportador de alimento e "[...] matérias-primas para os países ricos. O regime de trabalho explorava a mão-de-obra do escravo, que, por sua vez, era quem mantinha o desenvolvimento das fazendas" (NASCIMENTO, 2004, p. 42).

A ideia de criar timidamente algumas escolas para a população livre, principalmente para os ingênuos, em primeiro lugar, e, posteriormente para os ex-escravos, surgiu com o objetivo de preparar esses homens para trabalhar na indústria, porém com muita desconfiança por parte dos escravocratas, que viam a experiência de outros países, conforme as observações do engenheiro H. A. Milet sobre a experiências de outros países

[...] onde se tem realisado a emancipação da raça africana, prova que não se pode contar com os ingenuos para os trabalhos permanentes da Grande Lavoura, excepto, talvez, os que o Estado educar nas colonias agrícolas, que não pode deixar de fundar desde já. Os que ficarem nos engenhos, para pagarem com os seus serviços até 21 annos o dispêndio de sua criação, os abandonarão logo que chegarem a maioridade legal e forem senhores de suas acções" (CONGRESSO AGRÍCOLA DO RECIFE, 1878, 316).

Nos Congressos Agrícolas, no Rio de Janeiro e no Recife os proprietários apontaram a necessidade de desenvolver o ensino primário ${ }^{8}$ aliado aos interesses da agricultura, para suprir as fazendas com mão-de-obra, que não mais poderiam obter escravos do tráfico. O discurso que existia de "falta de braços" não se sustentava, pois a maioria da população livre era pobre e precisava trabalhar para alimentar a si e à sua família. O que se evidenciava era a falta de mão-de-obra escrava. Com isso os escravocratas se aproveitavam da fragilidade em que se encontravam os ingênuos e propunham a educação que desejavam para as crianças e jovens das cidades para que os [...] patrícios aprendam o que ignoram, aprendam a trabalhar e a aproveitar-se das nossas riquezas naturaes; venham fazendas modelos (CONGRESSO AGRÍCOLA DO RECIFE, 1878, 373). 


\section{Considerações Finais}

Na segunda metade do século XIX, a sociedade brasileira intensificou as discussões sobre a questão do fim da escravidão. Com a promulgação da Lei do Ventre Livre em 1871, a classe dominante composta principalmente de grandes fazendeiros de café, iniciou a criação de instituições a fim de receber os primeiros (ingênuos) "libertos", assim como propôs a criação de asilos e orfanatos de educação agrícola para receber e preparar as crianças para o trabalho.

A elite agrária tinha clareza de seu papel. Tanto que a educação proposta era a que lhe convinha, consciente de que os recursos necessários para implantação de escolas seriam fornecidos por ela. Para os congressistas as boas intenções do governo não podiam ser eficazmente realizadas sem o concurso das classes a que esse intuito mais interessava.

No longo período do escravismo no Brasil foram criadas pouquíssimas escolas, porém a educação escolar sempre esteve presente nos discursos governamentais como solução de todos os problemas. De fato, a escola proclamada não passou de uma "planta exótica", pois as instituições destinadas à formação de mão de obra para o trabalho agrícola sequer chegaram a ser implantadas com a amplitude proclamada nos discursos.

As pessoas consideradas livres eram parte do projeto do Governo Imperial e também dos grandes fazendeiros que queriam aproveitar promovendo a instrução para o trabalho por meio da criação de escolas públicas e colégios. Juntamente com esse projeto se verifica que, nos congressos, principalmente o de Pernambuco, entre as solicitações haviam as que apontassem a necessidade do poder público intervir na mão-de-obra para a construção nas cidades.

Assim, a concepção de instituição escolar pública (escola e ensino) defendida nos dois Congressos Agrícolas se concretizou após a abolição da escravidão, buscando atender aos interesses dos fazendeiros principalmente da região sudeste, pela forma diminuta como foram criadas as escolas públicas para a classe mais pobre no país.

\section{Fontes Primárias}

CONGRESSO AGRÍCOLA DO RIO DE JANEIRO: collecção de documentos. Rio de Janeiro: Typographia Nacional, 1878.

CONGRESSO AGRÍCOLA DO RECIFE, outubro de 1878. Sociedade Auxiliadora de Agricultura de Pernambuco (1978). Edição Fac-similar Comemorativa ao Primeiro Centenário. Recife. Fundação Estadual de Planejamento Agrícola de Pernambuco.

\section{Referências}

AITA, Carmen S. A. Liberalismo \& República: o pensamento político de J. F. de Assis Brasil. Porto Alegre: Tese de doutorado em História, PUCRS, 2006.

ALBUQUERQUE, Wlamyra Ribeiro de, FRAGA FILHO, Walter. Uma história do negro no Brasil. Universidade Federal da Bahia. Centro de Estudos Afro-Orientais, Fundação Cultural Palmares, 2006

ALMEIDA, José Ricardo Pires de. História da instrução pública no Brasil (1500-1889). São Paulo: EDUC ; Brasília, DF: INEP/MEC, 1989

ANTONIL, A. J. Cultura e opulência do Brasil. Vol. 2. São Paulo: Companhia Editora Nacional, 1967. (Coleção Roteiro do Brasil). 
BEIGUELMAN, Paula. A Formação do povo no complexo cafeeiro. São Paulo, Edusp, 1968. CHALHOUB, Sidiney. Visões da Liberdade: uma História das Últimas Décadas da Escravidão na Corte. São Paulo: Cia das Letras, 1990.

CHIAVENATO, Júlio José. O Negro no Brasil: da senzala à abolição. São Paulo: Moderna , 1999.

CORREA, Roberto Lobato. Região e organização espacial. São Paulo: Ática, 1987

COUTY, Louis. O Brasil em 1884: Esboços sociológicos. Rio de Janeiro: Fundação casa de Rui Barbosa, Brasília - Senado Federal, 1984.

DEAN, W. Rio Claro: um sistema brasileiro de grande lavoura. Rio de Janeiro: Paz e Terra, 1977.

DEL PRIORE, Mary e VENÂNCIO, Renato. Uma História da Vida Rural no Brasil. Rio de Janeiro: Ediouro, 2006

FERLINI, Vera Lucia Amaral. Uma fábrica colonial: trabalhos e técnicas nos engenhos brasileiros In: VIEIRA, Alberto (Org.). História e Tecnologia do Açúcar. Funchal: CEHA, 2000, p. 183-206.

Terra, Trabalho e Poder, São Paulo, Brasiliense, 1988.

FERNANDES, Florestan. A integração do negro na sociedade de classes. São Paulo: Dominus, USP, 1965.

, A revolução burguesa no Brasil: ensaio de interpretação sociológica. Rio de Janeiro: Zahar Editores, 1975.

FERNANDES, H. R. A Força Pública Do Estado De São Paulo. In: Boris Fausto História geral da civilização brasileira, v. 9, p.244.

FONSECA, Marcus V. A Educação dos Negros: Uma nova face do processo de abolição da escravatura no Brasil. São Paulo: Edusp, 2002.

FONSECA, Marcus V. Escolas para crianças negras: uma análise a partir do congresso agrícola do Rio de Janeiro e do Congresso Agrícola do Recife em 1878. In: III Congresso Brasileiro de História da Educação, 2004, Curitiba. SBHE, 2004.

MARTINEZ, Alessandra Frota. Educar e instruir: a instrução popular na Corte imperial. 1870 1889. Dissertação de Mestrado, Niterói, Universidade Federal Fluminense, 1997

MATTOS, Hebe Maria. Das cores do silêncio: Os significados da liberdade no sudeste escravista. Brasil, séc. XIX. 3a ed. Rio de Janeiro: Nova Fronteira, 1998.

MATTOSO, Katia M. de Queirós. Ser Escravo no Brasil. Brasiliense: São Paulo,1982.

MILET, Henrique Augusto. Os Quebra-Quilos E A Crise Da Lavoura. 2 ed. São Paulo: Global, 1987.

MOYSÉS. S. M. A. Leitura e apropriação de textos por escravos e libertos no Brasil do século XIX. Revista de Ciência e Educação - Educação e Sociedade. São Paulo: Papirus, n. ${ }^{\circ} 48$, agosto/1994

MOURA, Denise A. Soares.. Saindo das Sombras: Homens livres no declínio do escravismo. Campinas: CMU/Fapesp/Unicamp, 1998.

MOURA, Clóvis. Brasil: raízes do protesto negro. São Paulo: Global, 1983.

Rebeliões da senzala. Porto Alegre: Mercado Aberto, 1988

Dialética Radical do Brasil Negro. Editora Anita, 1994. 
NASCIMENTO, Maria Isabel Moura. A primeira escola de professores dos Campos Gerais PR. Tese de Doutorado. Campinas-SP: UNICAMP-FE, 2004

NASCIMENTO, Manoel Nelito M. HISTÓRIA, TRABALHO EDUCAÇÃo: Relações de produção e qualificação da força de trabalho na agroindústria canavieira. Tese de Doutorado. Campinas-SP: UNICAMP-FE, 2009.

PERRUCI, Gadiel. A república das usinas. Rio de Janeiro: Paz e Terra, 1978.

PINTO, R. P. A educação do Negro - uma revisão bibliográfica. In: Cadernos de Pesquisa, Fundação Carlos Chagas, São Paulo, 62, agosto/1987.

PINHEIRO, P.S. Classes médias urbanas: formação, natureza, intervenção na vida política. In: B. Fausto (org.). História geral da civilização brasileira, v. 9. São Paulo, Difel, 1989.

, P.S. O Proletariado Industrial na Primeira República. In: Boris Fausto (org.). História geral da civilização brasileira, v. 9, p. 146 e 149.

PRADO Jr., Caio. Formação do Brasil contemporâneo. 7a ed. São Paulo: Brasiliense, 1963.

RIBEIRO, Maria Luisa. História da Educação Brasileira. A organização escolar. ( $6^{\mathrm{a}}$ ed.) São Paulo: Moraes, 1986.

SCHELBAUER, Analete Regina. Ideias que não se realizam. $O$ debate sobre a educação do povo no. Brasil de 1870 a 1914. Maringá: Eduem, 1998.

SCHELBAUER, Analete Regina. Os congressos agrícolas de 1878 e o debate sobre a educação do povo no Brasil. In: Fórum Sul de coordenadores de pós-graduação em educação - ANPED. II Seminário de Pesquisa em Educação da Região Sul, 1999, Curitiba-PR: Imprensa UniversitáriaUFPR, 1999. p. 158

SIMÃO, André Luciano. Minas Gerais e o Congresso Agrícola de 1878: demandas, temores e percepções dos produtores rurais mineiros. In: Paula, João Antonio de and alli, et eds., Anais do XI Seminário sobre a Economia Mineira, Cedeplar, Universidade Federal de Minas Gerais. Disponível em: http://www.cedeplar.ufmg.br/diamantina2004/textos/D04A053.PDF Acesso em: 12/12/2012.

SIMÃO, André Luciano. Congressos Agrícolas de 1878: em retrato do reformismo ao final do século XIX. Dissertação de Mestrado em Sociologia, Universidade Estadual de Campinas, UNICAMP, 2001.

SINGER, Paul. O Brasil no Contexto do Capitalismo Internacional 1889-1930. In: FAUSTO, Boris (Dir.). História geral da civilização brasileira - O Brasil Republicano: estrutura de poder e economia. Tomo III v. 1 n. 8. 4 ed. São Paulo: Difel, 1985. P. 345-390

SOARES, Luiz Carlos. Os escravos de ganho no Rio de Janeiro do século XIX. Revista Brasileira de História, n. 16. mar., ago.1988.

TERRA, Paulo Cruz. Tudo que transporta e carrega negro? Carregadores, cacheiros e carroceiros no Rio de Janeiro (1824-1879) Dissertação de mestrado UFF, Niteroi, 2007.

Relações étnicas no setor de transportes: carregadores, cacheiros e carroceiros no Rio de Janeiro 1824-1870) Revista do Arquivo Geral da Cidade do Rio de Janeiro, N.3., 2009. VIOTTI DA COSTA, Emília, Da Monarquia à República. Momentos decisivos, $6^{\mathrm{a}}$ ed. São Paulo, Brasiliense, 1999 UNESP, 1998.

Da Senzala à Colônia. São Paulo, Ciências Humanas. $4^{\mathrm{a}}$. ed. São Paulo: Editora da A Abolição. 4. Ed. São Paulo: Ed. Global, 1986 


\section{Notas}

${ }^{1}$ Este artigo apresenta os resultados da pesquisa "Negro da senzala para escola: A educação nos Congressos Agrícolas do Rio de Janeiro e Pernambuco (1878)".

${ }^{2}$ Doutora em Educação e professora do Departamento de Educação da UEPG. Coordenadora do Grupo de Pesquisa História Sociedade da Educação nos Campos Gerais-PR (HISTEDBR).

${ }^{3}$ Doutor em Educação e professor do Departamento de Educação (DEd) da UFSCar (São Carlos). Membro do HISTEDBR

${ }^{4}$ Instituída em 1871, a Lei do Ventre Livre estabelece que os filhos de mulher escrava que nascerem a partir daquela data serão considerados de condição livre. No entanto, os filhos menores dos escravos ficavam em poder dos senhores de suas mães, os quais teriam a obrigação de criá-los e tratá-los até a idade de oito anos completos e podiam utilizar os serviços do menor até a idade de 21 anos completos.

${ }^{5}$ O Congresso Agrícola era composto de lavradores nacionaes ou estrangeiros que, por convite ou expontaneamente, a elle quizerem concorrer, , com tanto que oito dias do prazo marcado declarem, em carta fechada dirigida à Secretaria da Agricultura, a intenção de comparecer. Os lavradores, em seus respectivos municípios, poderão designar, d'entre si, um ou mais delegados, para represental-os no Congresso Agrícola (CONGRESSO AGRÍCOLA DO RIO DE JANEIRO, 1878, p. 2).

${ }^{6}$ Essa manifestação se deu por meio de correspondência encaminhada em resposta ao questionário, mesmo não tendo Irenêo Francisco de Souza e Silva participado do congresso por não ser da região sudeste.

${ }^{7}$ Sobre colônias agrícolas ver os estudos de Emília Viotti da Costa. E. Viotti. Da Senzala à Colônia. São Paulo: Unesp, 1998; de Fernando Henrique Cardoso sobre o Rio Grande do Sul, Capitalismo e escravidão no Brasil Meridional. São Paulo: Paz e Terra; de Octavio Ianni sobre o Paraná, As metamorfoses do escravo, Apogeu e crise da escravatura no Brasil Meridional. São Paulo: Hucitec, 1962; um texto com abrangência mais geral de Paula Beiguelman, A formação do povo no complexo cafeeiro: aspectos políticos. São Paulo: Pioneira,1968; de Florestan Fernandes, O negro no mundo dos brancos. São Paulo: Difusão Européia do livro, 1972.

${ }^{8}$ Após os intensos debates por parte dos escravocratas de todo o País, um ano após a realização dos congressos agrícolas, em 1879, o ministro do Império Leôncio de Carvalho decreta na Corte a reforma educacional, introduzindo o ensino de "noções de agricultura e horticultura", além de ofícios industriais, no currículo das escolas primárias de segundo grau, regulamentadas desde 1854, mas que não haviam se efetivado na Corte. 